\title{
Problems Affecting Gifted Children In Jordanian Schools
}

\author{
Ibrahim Al Shihab, Ph.D., Irbid National University, Jordan
}

\begin{abstract}
It is clear that there is a need for more attention to the social and emotional needs of the gifted students, as well as for increased attention to the affective needs of special populations of gifted students, such as underachievers, who are at risk for failure to achieve their potential. There is also a need for more empirical studies on the needs of these students, both in terms of preventative strategies such as affective curricula, and with regard to more intensive interventions such as individual, group, or family therapy. Good counseling models have been developed, but they need to be rigorously evaluated to determine the conditions under which they are most effective. In fact, researchers in the field of gifted education need to collaborate with researchers from affective fields such as personal and social psychology, counseling psychology, family therapy, and psychiatry, working together so the society can learn how to intervene most effectively with gifted individuals who have mental health problems and how to help all gifted persons achieve optimal social, emotional, and personal development.
\end{abstract}

Keywords: Gifted Children; Gifted Students

\section{INTRODUCTION}

ifted children face several challenges. They often develop at different rates emotionally, physically, and intellectually. Some people have is that these children don't do well socially. This is simply not true in most cases. Gifted children are able to reason better when conflicts arise and solve the problems. They are good at forming and keeping friends. Moreover, gifted children often prefer the company of older friends. When they're with others their age they have less in common and they may choose to go it alone. Some gifted children face frustration and boredom in the regular classroom. They need work at their level not simply more of it. This can get them branded a loner or unable to make friends when in reality this is not the case. Some gifted children face frustration and boredom in the regular classroom. In fact, teachers and parents need to be informed about the social and emotional needs of gifted children. Their support and encouragement goes a long way in building confidence and lets gifted children know that they have a right to learn.

Although possessing higher levels of intelligence than their peers, Gifted learners are disadvantaged in the sense that they frequently do not, or are not given the opportunity, to reach their full potential (Farmer, 1993). Krause, Bochner and Duchesne (2003) report that gifted learners are labeled, along with 'gifted', 'talented' or 'creative', as 'underachievers', 'educationally disadvantaged' or 'special needs.' This is primarily because schools and teachers are unaware of how to appropriately cater to these learners (Diezmann \& Watters, 2001; Langrehr, 2006).

Gifted children feel they are aliens or Martians. They often feel there is no place for them. They don't feel that they belong here. Their inner agenda, their joy of learning, penetrates to me so strongly, and yet, their voices are so seldom heard. In fact, test results close the doors to many gifted children, namely those who have difficulties with spelling, handwriting, or math computation. This, then, results in depression, because there is no outlet for their creativity. This is a picture that has often been presented to me by these children. Yet, the moment they see the understanding in their teachers and parents, it is as if a light bulb goes on, and the world is a beautiful place again. Gifted children have special learning needs, which if not met, can lead to frustration, boredom, a loss of self-esteem, underachievement and laziness (Crocker, 2004). If the gifted child is not recognized, he or she quickly becomes 
bored and disinterested with the content taught. Diezmann and Watters (2006) stated that gifted students have an advanced knowledge base compared to their non-gifted peers, so what is initially new content for non-gifted students might be only practice material for gifted students.' If the gifted student is not identified, they quickly surpass their non-gifted classmates and become accustomed to a relaxed approach to learning, which can create serious learning difficulties when confronted with difficult and complex material in higher studies (Diezmann \& Watters, 2006).

Langrehr's (2006) suggests that there are different categories of 'Giftedness,' primarily highlighting the difference between the creative mind and the critical mind - Langrehr suggests that these two mindsets, although markedly different, need to be treated as equally gifted. Actually, he challenges the 'higher-intelligence' method. The failure to identify the gifted child is further compounded by disagreement over exactly what constitutes 'gifted'.

\section{SIGNIFICANCE OF THE STUDY}

The problem of the gifted learners self-esteem and self-concept has emerges once the gifted child has been identified and placed into a higher streaming class. Actually, gifted students consciously place themselves at a higher level than their non-gifted peers, whilst simultaneously realizing the difference between the two. Diezmann, Watters and Fox (2001) claim that gifted children experience socio-emotional problems that include difficulty with social relationships, pressures to conform, resistance towards authority, isolation from peers, refusal to complete routine and repetitious work, and frustration with everyday life (Davis \& Rimm, 1998). They also note that these problems are frequently not resolved by school-leaving age, and may persist into later studies and life. Berger (2006) addresses the issue of gifted student's self-concept, claiming that due to gifted student's tendency to be a latebloomer, combined with their sensitivity to higher expectations and uneven social development can create a sense of displacement or dissonance. A student's level of social and emotional maturation may not keep pace with his or her advanced intellectual development, it is this social experience, attained through peer contact that many Talented and Gifted programs neglect or overlook.

\section{STATEMENT OF THE PROBLEM}

Many parents are excited when their child is identified as gifted. However, there are some social and emotional problems related to a child's is being gifted. Knowing what these problems are can help a parent identify them and solve the problems when they arise.

In Jordan, society places a heavy emphasis on being "normal". Gifted children with their high vocabularies and different ways of thinking make them different than their peers. They are on a completely different plane mentally than their peers of the same age and physical ability. These gifted children may be rejected by their peers for being different and the gifted child will feel the social pressure to fit in. When gifted children are with gifted peers or adults, they tend to maintain their high vocabulary and achieve to their potential. Gifted children face many social and emotional problems in the society and the researcher tried to investigate these problems.

\section{PURPOSE OF THE STUDY}

The purpose of this study is to investigate the social and emotional challenges that are facing gifted students in Jordanian schools, and to investigate the effect of gender on these problems.

\section{QUESTIONS OF THE STUDY}

1. What are the problems facing gifted students?

2. Are there any statistically significant differences in the degree of social problems facing gifted students?

3. Are there any statistically significant differences in the degree of emotional problems facing gifted students?

4. Are there any statistically significant differences in the social problems facing gifted students due to gender?

5. Are there any statistically significant differences in the emotional problems facing gifted students due to gender? 


\section{LIMITATIONS OF THE STUDY}

This study is limited to the children in King Abdallah school in Irbid $1^{\text {st }}$ Directorate of Education.

\section{LITERATURE REVIEW}

Some studies provide an illustrative sampling of the research on social and emotional issues among high ability youth. These studies are not exhaustive because many research studies on social and emotional issues have been published in journals outside the field of gifted education. Much of the empirical literature on social and emotional issues of gifted students uses causal comparative designs to compare characteristics of students who have been identified as gifted with one or more comparison groups. The comparison groups are sometimes students who are achieving at average levels; at other times the comparison groups are subpopulations of gifted students. Some studies include both types of comparisons. Studies comparing subpopulations of gifted students have created groupings based on variables such as level of giftedness and psychological characteristics. The studies in this volume are good examples of the quantitative comparison literature.

Actually, early studies on social and emotional issues tended to focus on comparing the social and emotional characteristics of academically gifted students and students who were achieving or functioning at average levels. The oldest study in this collection of seminal studies was one of the first studies of this type to focus on young children (Lehman \& Erdwins, 1981).

Lehman and Erdwins compared third-grade students enrolled in a gifted program in a suburban public school with children in the same school in grades three and six who had average IQ scores (range $=90-110$ ), a gifted student versus chronological age comparison group vs. mental age comparison or CA-MA design. They found that gifted students exhibited excellent personal and social adjustment, especially with respect to their CA peers. With respect to their MA peers, gifted third graders were superior to the sixth graders on several personal and social variables (such as self-esteem, sense of personal freedom, family relations, and lack of antisocial tendencies) and similar on others (such as self-direction, withdrawal tendencies, social standards, and social skills). The only area where the gifted students showed less positive adjustment than their MA peers was on nervous symptoms. These findings suggest that gifted children who are participating in gifted programs in suburban school districts have strong families and self-esteem and precocious social and self-direction skills.

Kaiser and Berndt (1985) assessed a group of high school students attending a Governor's school on a variety of emotional variables including stressful life changes, anger, depression, and loneliness. Although they found the group to be relatively well-adjusted overall, 15-20\% reported significant distress on one or more of the measures used.

These researchers used regression analyses, they were able to determine that depression, stress, and anger predicted loneliness among these gifted students then they moved beyond description to prediction. This method of studying within group differences has three advantages. First, it demonstrates that even though most gifted students are well-adjusted, a minority may be at risk for social/emotional problems. Second, regression designs retain all of the information in continuous variables and most social/emotional assessment scales are continuous in nature. Third, prediction models may be able to identify specific gifted students who are at risk for social/emotional adjustment problems and/or might benefit from counseling.

Sowa and May (1997) create a prediction model for functional and dysfunctional patterns of adjustment among gifted students by using qualitative research. Their model was based on observations of students and interviews with families, teachers, and friends about coping styles. Although their sample was small, as is typical in qualitative research, it was one of the few samples in the social/ emotional literature that was diverse. Out of 20 students 7 (35\%) were ethnic minorities. The model they developed uses both environmental variables (family functioning) and individual variables (adjustment mechanisms) to predict social/emotional adjustment. This study also provides a theoretical framework for developing and evaluating interventions to increase the resilience of gifted students by targeting family functioning and/or individual coping styles. It provides guidance on family and psychological risk factors that can increase the chances that gifted students will experience adjustment difficulties. 
Coleman (2001) in his study gets inside the heads of gifted adolescents, helping us to understand what they experience in an academically rigorous, residential environment. The study suggests that residential schools for gifted adolescents can facilitate the creation of an atypical adolescent social system with many positive characteristics such as appreciation of diversity, support for academic achievement, and absence of physical violence. The study also highlights some of the stressors that gifted students can experience in this type of environment such as busy schedules, omnipresent deadlines, and pressure.

\section{DESIGN AND METHODOLOGY}

\section{Population of the study}

The population of the study consisted of all gifted students at King Abdullah School in Irbid the $1^{\text {st }}$ Directorate of Education.

\section{Sample of the study}

The sample of the study comprised of (47) gifted students from king Abdullah School, and a questionnaire was distributed among them, 20 male and 27 female students.

\section{Instrument of the study}

A questionnaire was distributed among the students and this questionnaire was designed by the researcher himself, it consisted of 20 items. Many variables were included such as the gender of the students and the types of challenges (emotional and social).

\section{Reliability of the instrument}

To ensure the questionnaire reliability, the researcher applied it to a pilot sample of (10) students excluded of the study sample in the same school from which the subjects were chosen with a two-week period between the first and second time it was distributed. The reliability of the test was calculated using correlation coefficient.

\section{Procedures of the study}

This study was quantitative in nature. At the beginning of the study, a questionnaire about problems facing gifted students was given to 47 gifted students in king Abdullah School in Irbid. After that the researcher collected the questionnaires and collected data, and then this data was analyzed statistically.

\section{Statistical analysis}

The results were analyzed for each item in the questionnaire using suitable statistical methods such as mean and standard deviation, then the researcher dealt with each rank separately (emotional and social). The researcher also used figures to clarify the results more.

\section{Findings of the Study}

The purpose of this study is to investigate the social and emotional challenges that are facing gifted students in Jordanian schools, and to investigate the effect of gender on these problems.

To answer the first question about problems affecting gifted students: What are the problems facing gifted students? A questionnaire was distributed among them and means and standard deviation were calculated. Results were shown in Table 1. 
Table 1: problems facing gifted students

\begin{tabular}{|c|c|c|c|}
\hline Rank & & Mean & Std. Deviation \\
\hline 1 & Q1 & 4.34 & 1.002 \\
\hline 2 & Q4 & 4.32 & .949 \\
\hline 3 & Q7 & 4.28 & .994 \\
\hline 4 & Q8 & 4.28 & 1.214 \\
\hline 5 & Q14 & 4.24 & .931 \\
\hline 6 & Q2 & 4.21 & .914 \\
\hline 7 & Q19 & 4.19 & 1.000 \\
\hline 8 & Q17 & 4.17 & 1.227 \\
\hline 9 & Q3 & 4.15 & 1.035 \\
\hline 10 & Q18 & 1.042 \\
\hline 11 & Q20 & 4.13 & 1.318 \\
\hline 12 & Q5 & 4.13 & 1.083 \\
\hline 14 & Q13 & 4.04 & .830 \\
\hline 15 & Q16 & 4.04 & 1.022 \\
\hline 16 & Q6 & 4.00 & 1.299 \\
\hline 18 & Q15 & 3.98 & 1.021 \\
\hline
\end{tabular}

Table 1 shows the problems facing gifted students; means and standard deviations were calculated. 47 students answered the questionnaire and the highest mean was (4.34) for the $1^{\text {st }}$ question. The lowest mean was (3.70) for the $11^{\text {th }}$ question. Standard deviation for the $1^{\text {st }}$ question was not statistically significant as it was (0.962) which is higher than $(\alpha \leq 0,05)$. The total items standard deviation was $(0,901)$ which is not significant. Questions 1 , $7,8,2,17$ and 6 showed that they have not statistically significant differences at the level $(\alpha \leq 0,05)$ when they were (0.962, 0.940, 0.994, 0.931, 0.996 and 0.830 respectively).

To answer the second question about social problems: Are there any statistically significant differences in the degree of social problems facing gifted students? Table 2 shows the results.

Table 2: T-Test (social problems facing gifted children)

\begin{tabular}{|c|c|c|c|}
\hline Rank & Social & Mean & Std. Deviation \\
\hline 1 & Q1 & 4.34 & .962 \\
\hline 2 & Q4 & 4.32 & .002 \\
\hline 3 & Q7 & 4.28 & .949 \\
\hline 4 & Q8 & 4.28 & .994 \\
\hline 5 & Q2 & 4.21 & 1.000 \\
\hline 6 & Q3 & 4.15 & 1.042 \\
\hline 7 & Q5 & 4.04 & .830 \\
\hline 8 & Q6 & 3.98 & 1.299 \\
\hline 10 & Q10 & 3.96 & 1.237 \\
\hline
\end{tabular}

Table 2 shows the social problems facing gifted students; means and standard deviations were calculated. 47 students answered the questionnaire and the highest mean was (4.34) for the $1^{\text {st }}$ question. The lowest mean was (3.77) for the $9^{\text {th }}$ question. Standard deviation for the $1^{\text {st }}$ question was not statistically significant as it was (0.962) which is higher than $(\alpha \leq 0,05)$. The total items standard deviation was $(0,866)$ which is not significant. All questions showed that they have not statistically significant differences at the level $(\alpha \leq 0,05)$. 


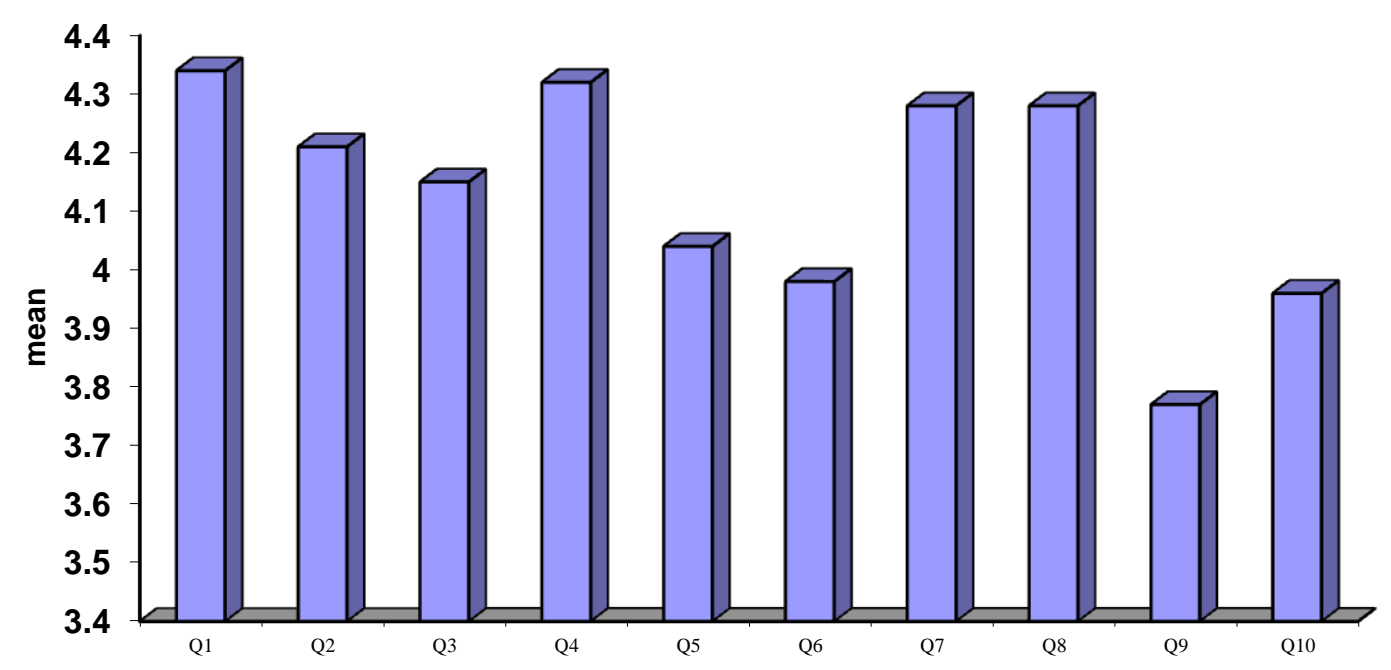

Diagram 1: social problems facing gifted children

Diagram 1 shows that questions $1,4,7$, and 8 got the highest means.

To answer the third question about emotional problems: Are there any statistically significant differences in the degree of emotional problems facing gifted students? Table 3shows the results.

Table 3: T-Test (emotional problems facing gifted children)

\begin{tabular}{|c|c|c|c|}
\hline Rank & Emotional & Mean & Std. Deviation \\
\hline 1 & Q14 & 4.24 & 1.214 \\
\hline 2 & Q19 & 4.19 & 1.014 \\
\hline 3 & Q17 & 4.17 & .996 \\
\hline 4 & Q18 & 4.13 & 1.227 \\
\hline 5 & Q20 & 4.13 & 1.035 \\
\hline 6 & Q13 & 4.04 & 1.318 \\
\hline 7 & Q16 & 4.00 & 1.083 \\
\hline 8 & Q15 & 3.98 & 1.022 \\
\hline 9 & Q12 & 3.96 & 1.021 \\
\hline
\end{tabular}

Table 3 shows the emotional problems facing gifted students; means and standard deviations were calculated. 47 students answered the questionnaire and the highest mean was (4.24) for the $14^{\text {th }}$ question. The lowest mean was (3.70) for the $11^{\text {th }}$ question. Standard deviation for the $14^{\text {th }}$ question was not statistically significant as it was (1.214) which is higher than $(\alpha \leq 0,05)$. The total items standard deviation was $(1,001)$ which is not significant. All questions showed that they have not statistically significant differences at the level $(\alpha \leq 0,05)$. 


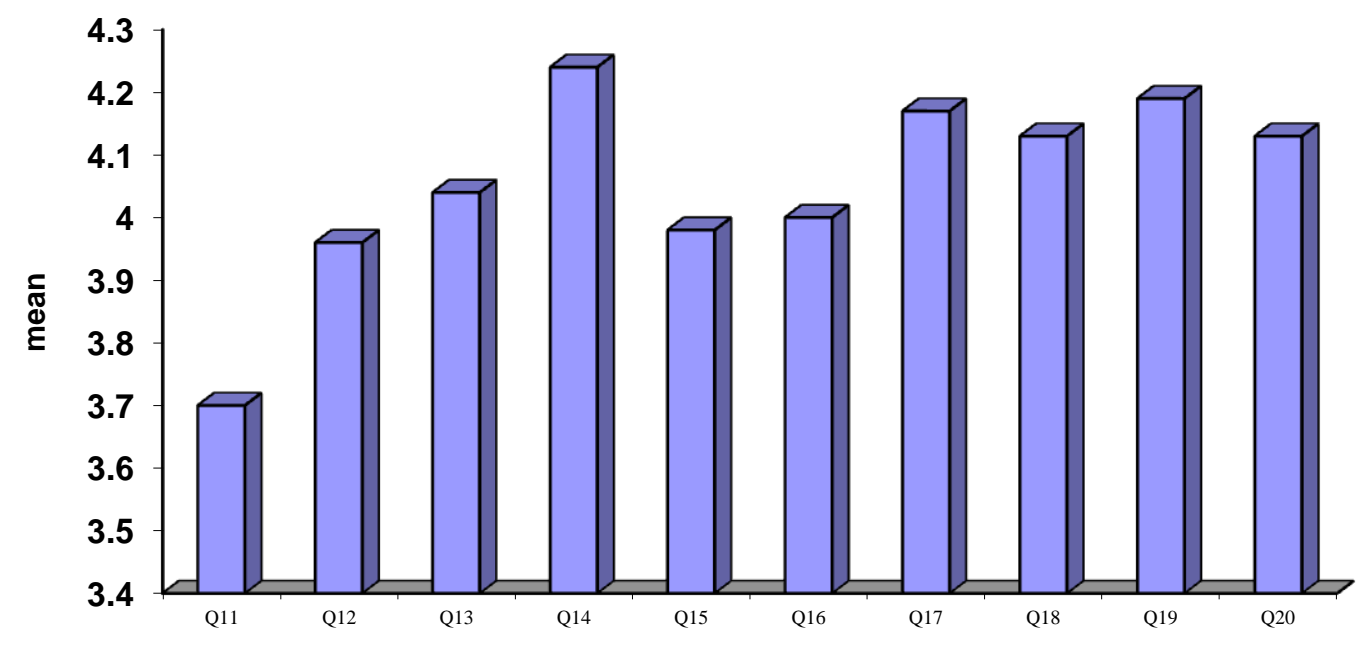

Diagram 2: emotional problems facing gifted children

Diagram 2 shows that question 14,17 , and 19 got the highest means.

To answer the fourth question about the effect of gender on social problems facing gifted students: Are there any statistically significant differences in the social problems facing gifted students due to gender? Table 4 shows the results.

Table 4: effect of gender on social problems

\begin{tabular}{|c|c|c|c|c|c|c|c|}
\hline & Gender & N & Mean & Std. Deviation & t & df & Sig. (2-tailed) \\
\hline Social & Male & 20 & 4.14 & .869 & .014 & 45 & .988 \\
\hline & Female & 27 & 4.13 & .881 & & & \\
\hline
\end{tabular}

Table 4 shows there are no statistically significant differences due to gender variable. It shows the results of the questionnaire which was distributed among (47) male and female gifted students about social problems they face. Means and standard deviations were calculated and results show that males got a little bit higher mean which was (4.14); this indicates that male gifted students face many social problems. Females got a little bet lower mean than males which was (4.13).

Standard deviation for males was (0.869) which is higher than $(\alpha \leq 0,05)$ so it means that it is not statistically significant. Standard deviation for females was nearly the same; it was (0.881) which is also not statistically significant. So, there is no statistically significant difference in the social problems facing gifted students due to gender variable.

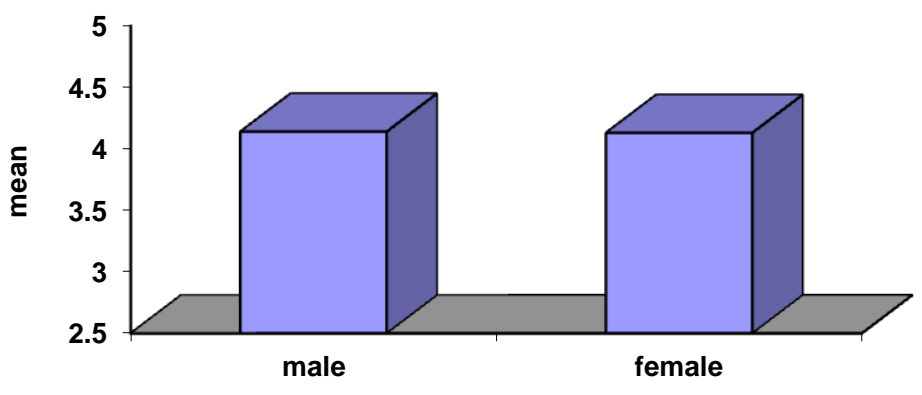

Diagram 3: effect of gender on social problems 
Diagram 3 shows the results of the social problems facing gifted students due to their gender, a questionnaire was distributed among 47 students and as it is clear here males got a little bit higher mean than females.

To answer the fifth question about the effect of gender on emotional problems facing gifted students: Are there any statistically significant differences in the emotional problems facing gifted students due to gender? Table 5 shows the results

Table 4: effect of gender on emotional problems

\begin{tabular}{|l|l|c|c|c|c|c|c|}
\hline & Gender & $\mathbf{N}$ & Mean & Std. Deviation & t & df & Sig. (2-tailed) \\
\hline Emotional & Male & 20 & 4.06 & .903 & .161 & 45 & .873 \\
\hline & Female & 27 & 4.02 & 1.085 & & & \\
\hline
\end{tabular}

Table 5 shows there are no statistically significant differences due to gender variable. It shows the results of the questionnaire which was distributed among (47) male and female gifted students about social problems they face. Means and standard deviations were calculated and results show that males got a little bit higher mean which was (4.06); this indicates that male gifted students face many emotional problems. Females got a little bet lower mean than males which was (4.02).

Standard deviation for males was $(0.903)$ which is higher than $(\alpha \leq 0,05)$ so it means that it is not statistically significant. Standard deviation for females was nearly the same; it was (1.085) which is also not statistically significant. So, there is no statistically significant difference in the emotional problems facing gifted students due to gender variable.

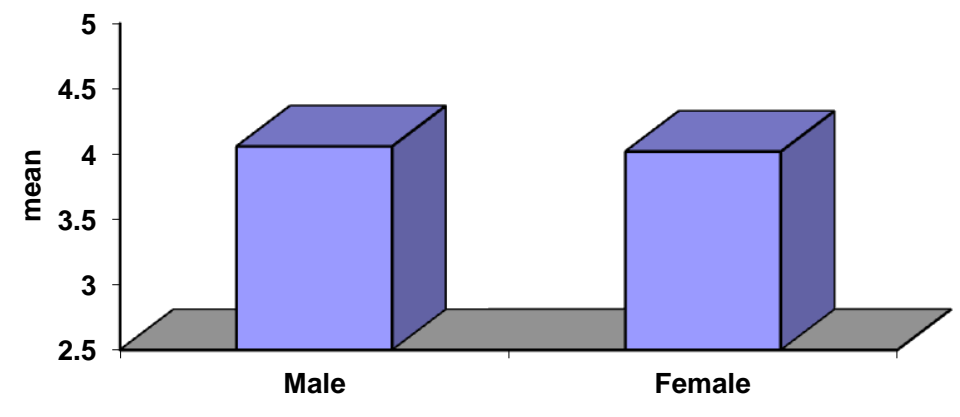

Diagram 4: effect of gender on emotional problems

Diagram 4 shows the results of the emotional problems facing gifted students due to their gender, a questionnaire was distributed among 47 students and as it is clear here males got a little bit higher mean than females.

\section{CONCLUSION}

It is clear that there is a need for more attention to the social and emotional needs of the gifted students, as well as for increased attention to the affective needs of special populations of gifted students, such as underachievers, who are at risk for failure to achieve their potential. There is also a need for more empirical studies on the needs of these students, both in terms of preventative strategies such as affective curricula, and with regard to more intensive interventions such as individual, group, or family therapy. Good counseling models have been developed, but they need to be rigorously evaluated to determine the conditions under which they are most effective. In fact, researchers in the field of gifted education need to collaborate with researchers from affective fields such as personal and social psychology, counseling psychology, family therapy, and psychiatry, working together so the society can learn how to intervene most effectively with gifted individuals who have mental health problems and how to help all gifted persons achieve optimal social, emotional, and personal development. 


\section{AUTHOR INFORMATION}

Dr. Ibrahim Al Shihab, Irbid National University, Jordan. E-mail: Dr.shihab55@ yahoo.com

\section{REFERENCES}

1. Coleman, L. J. (2001). A "rag quilt": Social relationships among students in a special high school. Gifted Child Quarterly, 45(3), 164-173.

2. Crocker, T. (2004) "Underachievement: Is our vision too narrowed and blinkered? 'Fools step in where angels fear to tread." in Gifted 131:10-14

3. Diezmann, C.M and Watters, J.J. (2006) "Balancing Opportunities for Learning and Practicing for Gifted Students" in Curriculum Matters 5(1):3-5.

4. Diezmann, C.M., Watters, J.J., and Fox, K. (2001) "Early entry to school in Australia: Rhetoric, research and reality" in Australasian Journal for Gifted Education 10(2):5-18.

5. Farmer, D. (Ed.) (1993) Gifted Children need help? A guide for parents and teachers. Strathfield: NSW: NSW Association for Gifted and Talented Children.

6. Krause, K., Bochner, S., Duchesne, S. (2003). Educational Psychology for learning and teaching. Southbank, Victoria: Thomson.

7. $\quad$ Langrehr, J. "New ways for identifying gifted thinkers." in Gifted 140:11-14.

8. Kaiser, C. R., \& Berndt, D. J. (1985). Predictors of loneliness in the gifted adolescent. Gifted Child Quarterly, 29(2), 74-77.

9. Lehman, E. B., \& Erdwins, C. J. (1981). The social and emotional adjustment of young, intellectuallygifted children. Gifted Child Quarterly, 25(3), 134-137.

10. Sowa, C. J., \& May, K. M. (1997). Expanding Lazarus and Folkman's paradigm to the social and emotional adjustment of gifted children. Gifted Child Quarterly, 41(2), 36-43. 
NOTES 